\title{
Ruined Archeological Heritage. Survey, 3D Modeling, Virtual Anastylosis
}

by

Fabrizio Agnello and Mirco Cannella

Reprinted from

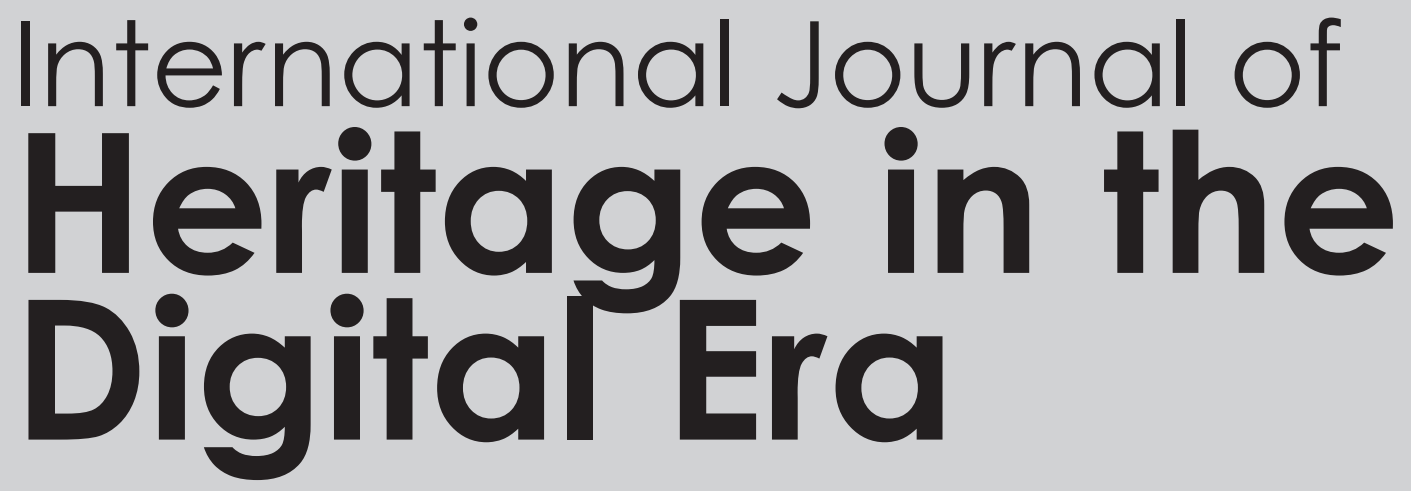

volume 2 number 32013 


\section{Ruined Archeological Heritage. Survey, 3D Modeling, Virtual Anastylosis}

Fabrizio Agnello and Mirco Cannella

Dept. of Architecture, University of Palermo

Viale delle Scienze, Palermo, Italy;

Email: fabrizio.agnello@unipa.it and mirco.cannella@unipa.it 


\title{
Ruined Archeological Heritage. Survey, 3D Modeling, Virtual Anastylosis
}

Fabrizio Agnello and Mirco Cannella

\begin{abstract}
:
The study focuses on the use of 3D surveying and digital representation tools for the purpose of documenting archaeological monuments whose restoration involves the disassembly and repositioning of blocks. The case study in question is a building at the west end of the San Biagio archaic sanctuary, located within the archaeological site of Agrigento.
\end{abstract}

The monument is a rectangular building encompassing two pools, whose foundations are suffering from deep decay and there are large spaces between the walls which have become disconnected. Surveying and 3D modelling have been used to illustrate the existing state of the building. Plans, sections and orthophotos have been created to support the indexing of ashlars and to evaluate the structural decay. A 3D model of the most dilapidated part of the building, the north-eastern corner, has been constructed in order to document the direction of the ashlars and where they are positioned in relation to each other. Finally, a restoration model of this building been built.

\section{Introduction}

Agrigento, on the south coast of Sicily is world-renowned for its archaeological ruins; the most famous and frequented part is known as "Valley of the Temples", an east-west oriented long and narrow promontory not far from the coast, which is the site of the ruins of three Greek Temples. The San Biagio Sanctuary is located a short distance from the Temples, at the northeastern corner of the archaeological site. It is nestled in a natural hollow, where the west side is closed off by a rock. The combination of caverns in the rock and underground water made it the ideal location for a sanctuary dedicated to chthonic deities. In fact, a temple dedicated to Demeter was built not far from here (figure 1). 
Figure 1. The site: (a) Sicily, Agrigento;

(b) The "Temple Hill" (blue frame) and the Sanctuary area (red); (c)

Aerial view of the Sanctuary from East.

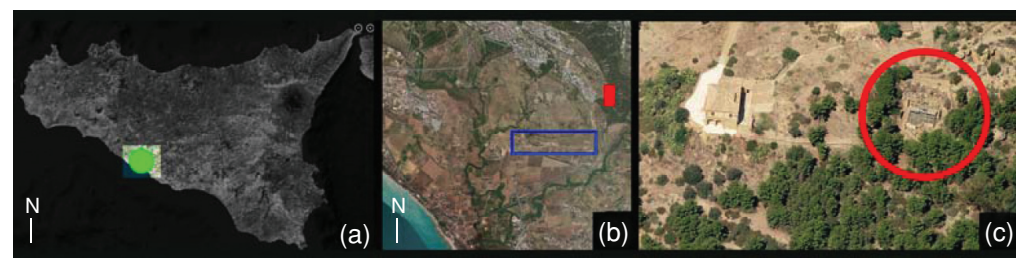

Archaeologists [10] do not all agree on the exact date of the sanctuary, but it is widely presumed that the building we can see today dates back to the $5^{\text {th }}$ century B.C. and that the hollow was the location of a sacred site as early as the $7^{\text {th }}$ century [9]. The sanctuary, which over time had been covered by layers of earth, was discovered by Pirro Marconi [8] in 1926, and the excavation of the site was carried out by Giuseppe Cultrera [3] in 1932.

The sanctuary is divided into two distinct areas: a north-south oriented rectangular building and an open area facing its east side (figure 2a). The building in its current state is nothing more than a rectangular 'box'. High stone walls (south-north oriented) run along its long sides and encompass two pools, which are separated by an east-west cross wall. There was presumably a roof at one time. There are two trapezoidal-shaped openings in both the east and west walls. A block, which originally belonged to a jutting cornice, can be seen in the highest part of the south-eastern corner; further fragments of the cornice can be found strewn on the ground around the sanctuary. Hydraulic systems, engineered in different phases [11], are still clearly detectable. Many blocks, especially at the lower levels, have holes in them to allow water filter through and fill up the pools, and then flow outside. The open area was walled and terraced on 3 levels [5] so as to better 'fit' into the east-west sloping land.

Soon after the excavations in 1932 (figure 2b), the structural decay started to affect the walls around the pools: the walls
Figure 2. The sanctuary: (a) Plan by Cultrera (the rectangular building is highlighted); (b) The east front after excavations (Courtesy Soprintendenza BB.CC.AA. Agrigento).
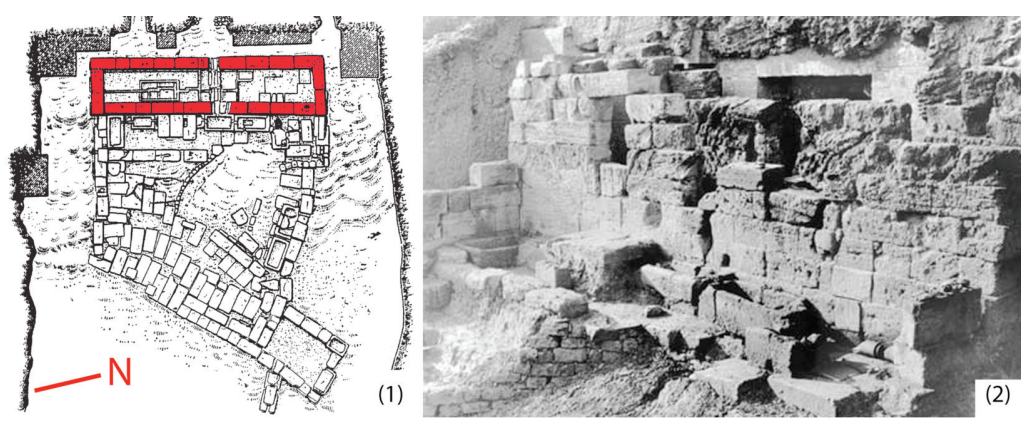
became slanted and the blocks started to come apart from each other [4]. This structural damage was presumably due to the nature of the ground beneath it, which is clayey and interspersed with underground channels. In fact the layer of earth which covered the building before its discovery seemed to have prevented its collapse for centuries.

The sanctuary was restored at the end of the 1970s, but this failed to prevent the collapse of the foundation blocks. This explains the network of scaffolding holding up the walls today (figures $3 a$ and $3 \mathrm{~b}$ ).

The rectangular building is situated close to a rock with caverns; the passage between the rock and the western front of the building is very narrow, ranging from $60 \mathrm{~cm}$ at the southern end to one metre at the northern end (Figure $3 \mathrm{c}$ ). The stone rectangular building is $12,70 \mathrm{~m}$ long and 3,25 $\mathrm{m}$ wide. The walls are made of limestone ashlars about $60 \mathrm{~cm}$ thick and positioned in 9 tiers, plus the cornice at the top. The top of the ninth tier stands almost $4.62 \mathrm{~m}$ above the bottom of the pools. The short walls are east-west oriented and perpendicular to the rock; the south-eastern corner is well-preserved, while in the northeastern corner the walls have come apart considerably; the stone blocks in this area have moved from their original position and some are broken.

This study focuses on the documentation of the entire building and on the virtual reconstruction of the north-eastern corner to aid the restoration project of the sanctuary. Orthophotos of the inner and outer facades of the walls have been produced; a 3D polygonal model has been extracted from the point cloud; finally a 3D 'block by block' model has been made of the north-eastern corner. This model, as outlined below, provides an effective support for the restoration as it allows indexing and also supports both virtual and real displacement and repositioning. (a)

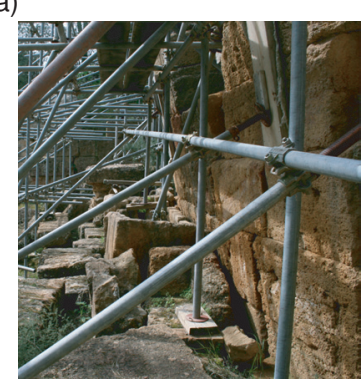

(b)

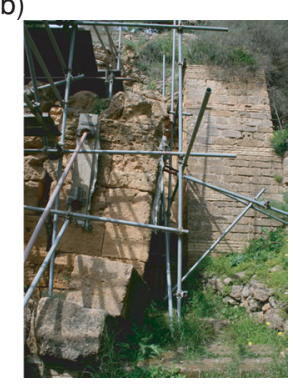

(c)

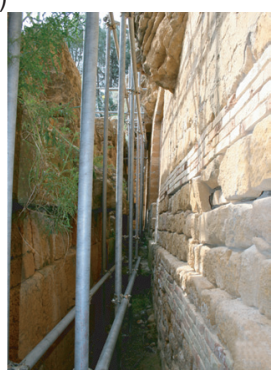

Figure 3. The rectangular building: (a) The northern end of the east front; (b) The north-eastern corner; (c) The narrow passage between the west front and the caverns. 


\section{Data Acquisition}

Before starting the data acquisition, we set up a topographic polygonal made of 7 vertices: three vertices, at the eastern end of the sanctuary area, were used to register the point clouds; three iron stands fixed deeply into the ground allow for the precise positioning of total stations and for a trustworthy support to the repetition of measurements for monitoring; the vertices on the iron stands could also be used to guide the repositioning of blocks throughout the restoration works.

The three main obstacles that we faced during the acquisition process were, firstly, the scaffolding enfolding the building, secondly the short cross extension of the pools and thirdly the narrowness of the passage between the western wall and the rock. Laser scans were employed in order to get comprehensive documentation of each visible face of the blocks. By stationing the laser device at varying points and heights, often close to each other, we were able to get a point cloud whose average resolution ranges from 5 to $7 \mathrm{~mm}$.

A further challenge was acquiring photographic documentation; most of the blocks were photographed from different viewpoints and wide angle lenses were used to photograph the blocks facing narrow spaces (figures 4, 5).

Topographic survey of targets was conducted both for registering point clouds from laser scans, and for scaling and referencing the point clouds which have been extracted with photogrammetric processing.

Figure 4. Data acquisition:

(a) Topographic survey; (b) Laser scanning survey; (b) Photogrammetric survey.

Figure 5. Registered Point clouds and iron stands (red highlights): (a) Plan view; (b) Perspective view. (a)

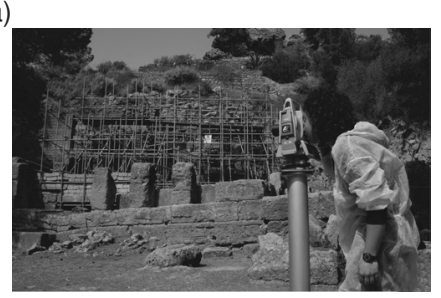

(b)

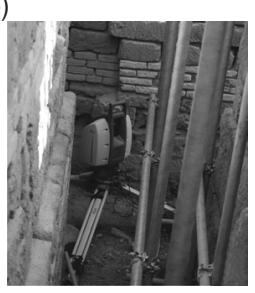

(c)

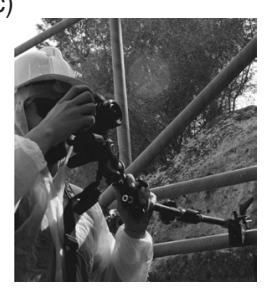

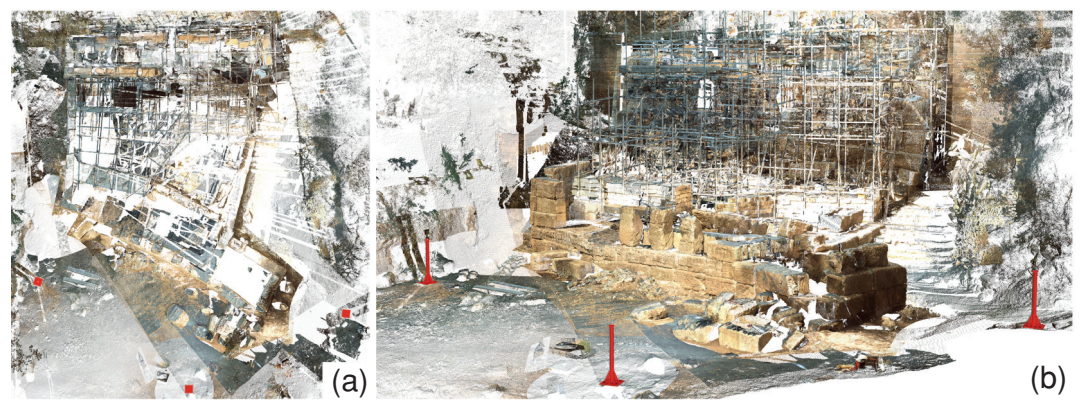




\section{Data Processing ${ }^{1}$}

Processing the data from the laser scanning followed a well-known process: point clouds were firstly filtered to remove unwanted data and then registered and referenced to the topographic coordinate system. Orthophotos of the inner and outer faces of the walls were created using photographic documentation of the fronts.

\subsection{Geometric analysis and graphic representation}

The point clouds were used to extract vertical and horizontal sections of the rectangular building; the horizontal sections were drawn so as to represent the actual position of the blocks on each tier (figure 6). The blocks were then numbered and classified to assist with indexing; the projection plan of the point cloud shows the mutual position of the tiers. The vertical sections effectively display the decay of the monument and were also used as a boundary for the orthophotos of the inner sides of the building (figure 7).

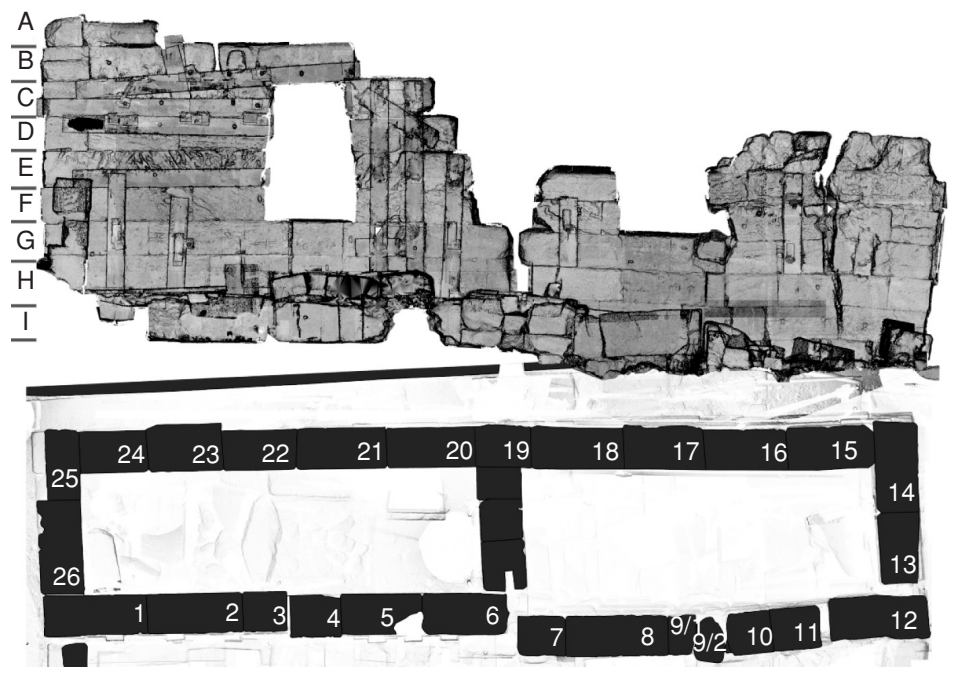

(a)

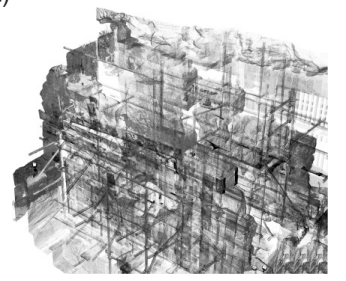

(b)

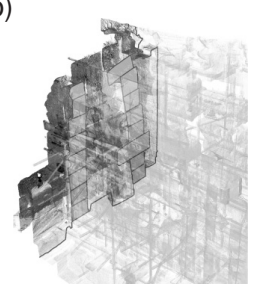

(c)

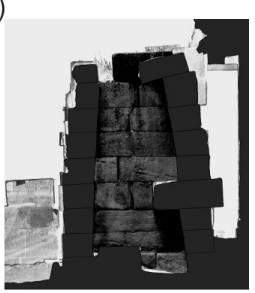

Figure 6. Mesh of the East front and Plan of the ' $G$ ' tier.
Figure 7. Vertical sections: (a) View of the Point cloud; (b) Vertical cross section; (c) Orthophoto of the inner face of the south front.

\footnotetext{
1 Leica Cyclone 8.0 was used in point cloud orientation, filtering, segmentation and triangulation; drawings and 3D models were created with Rhinoceros 5.0; photogrammetric processing was performed with Photomodeler 2013.
} 


\subsection{Orthophoto processing}

A varied procedure was developed for photogrammetric processing; due to the scaffolding and therefore the poor visibility of the blocks, the data from both topographic and laser scanning survey were used as a reference to scale and position images.

Blocks of orthophotos were loaded onto Photomodeler Scanner; the natural features of the blocks were automatically detected on the photos and a point cloud was extracted (figure 8). Targets fixed onto the fronts were measured with total stations and were then used to scale and reference the blocks of orthophotos onto the topographic coordinate systems. Targets on the external west facade and on the internal ones could not be measured with total stations. Instead, orthophotos of these areas were scaled and referenced using the natural features that were detectable in the point clouds. Finally, the processed orthophotos were exported in GeoTiff file format.

Point clouds from laser scanning survey were segmented to single out the internal and external faces of the rectangular building; point clouds were then triangulated and meshes were used as a reference

Figure 8. Photogrammetric processing: (a) Block of photos; (b) Colored Point cloud. (a)
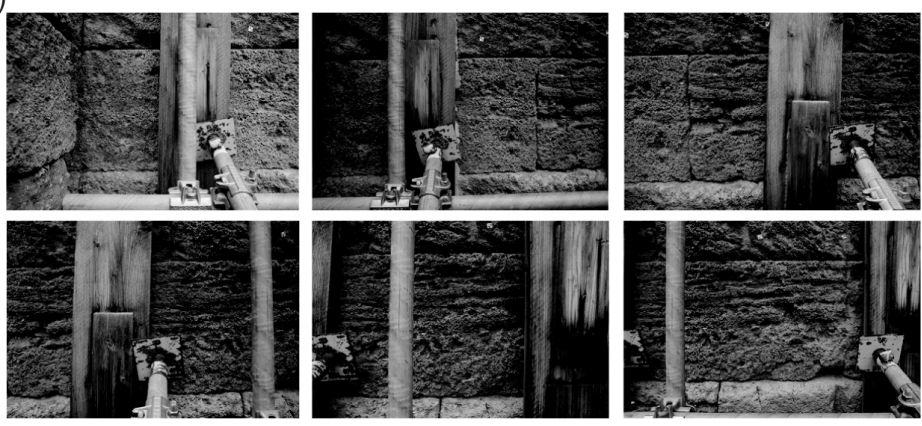

(b)

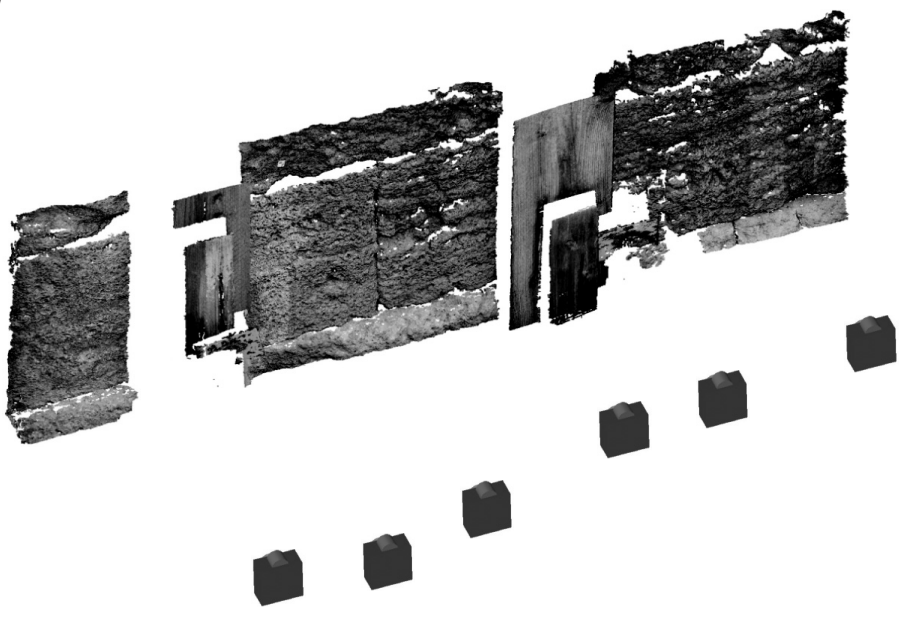

Ruined Archeological Heritage. Survey, 3D Modeling, Virtual Anastylosis 
to register the blocks of orthophotos. The meshes effectively show most of the peculiarities of the surface of the blocks (holes, fractures, picks) and these were used as 'natural points' in the orthophoto processing.

Blocks of orthophotos were mounted onto the GeoTiff orthoviews of the meshes; using photo editing tools the RGB values and levels in the images were adjusted in order to produce a uniform image (figure 9).

It must be mentioned that the elements touching the blocks, i.e. the timber planks placed between the iron supports and the eastern external facade, could not be removed either from the point cloud or from the orthophotos.

(a)

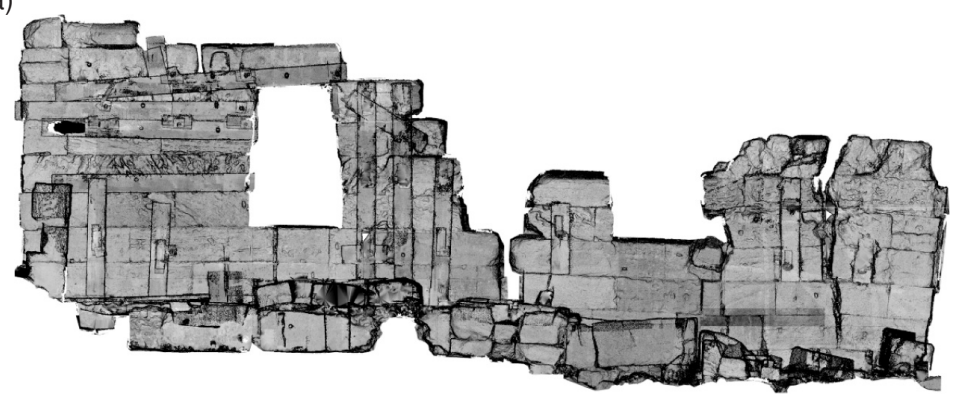

(b)
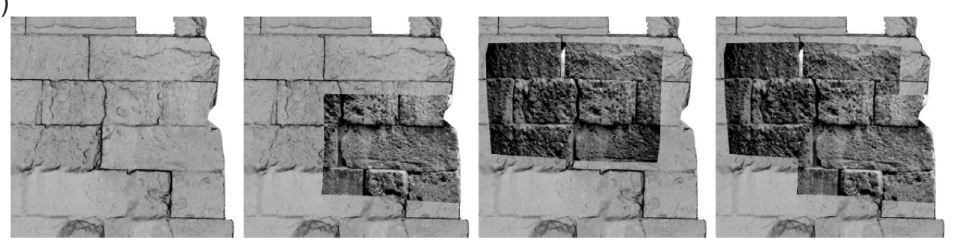

(c)

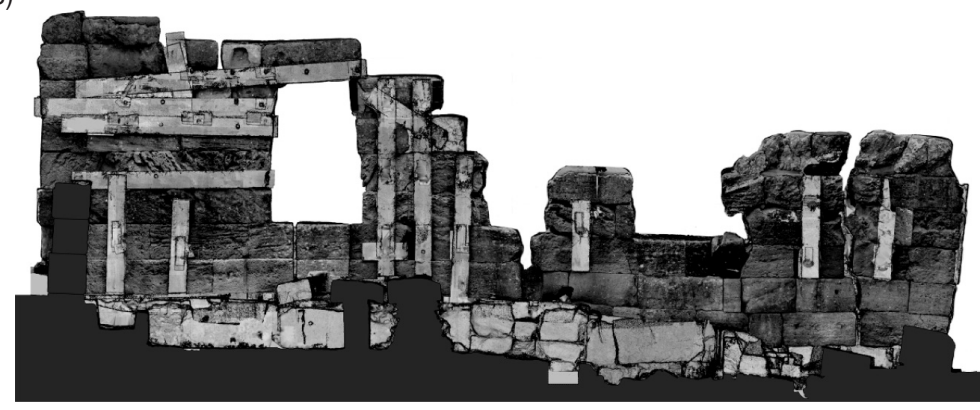

\subsection{Digital modeling}

The modelling process of the individual ashlars in the north-eastern corner of the building had to meet three specific demands: a) the interpolation of occluded faces [1], mainly the horizontal ones and also the vertical faces that are attached to other blocks, where no
Figure 9. Orthophoto processing:

(a) Front view of the mesh;

(b) Images registration; (c)

Orthophoto (mesh on occluded areas). 
data were available; b) customizing the resolution of the polygonal model $[6,7]$, according to the specific features of each ashlar (e.g. carvings, holes or surface abnormalities); c) the computational manageability of the model.

Each block was modelled as a single unit; the point cloud was therefore segmented in order to isolate the points of each ashlar from the whole cloud; during the segmentation process the detection of the upper and lower edges of each visible face had to be specially treated, since these edges are critical in the interpolation of occluded areas.

The semi-automatic modelling process used in this study can be detailed as follows (figure 10): in the first step a polygonal model of a box enveloping the ashlar is created; the box is roughly fitted onto the point cloud using vertexes-transformation tools; the model is then processed so as to increase the number of polygons and achieve a resolution that allows the proper documentation of the block's features; finally, the hi-poly model is fitted and remeshed onto the point cloud ${ }^{2}$.

Figure 10. Block Modeling: (a) Point cloud; (b) Polygonal model;

(c) Fitting; (d) Model. (a)

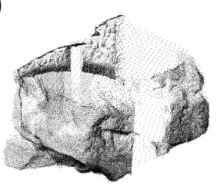

(b)

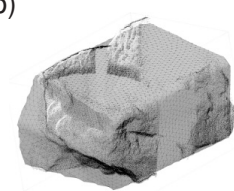

(c)

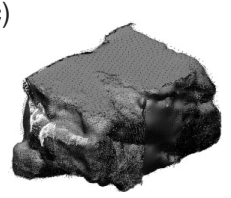

(d)

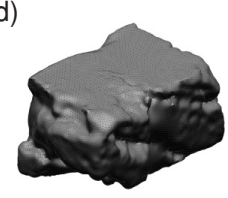

When particular features in the surface of the block required a more detailed resolution, the number of faces of the mesh was increased.

A relevant feature of the fitting process is the definition of the allowable deviation, i.e. the range within correspondences between the models are taken into account. The chosen allowable deviation ranges from 2 to $5 \mathrm{~cm}$ so that the mesh of occluded faces is not affected by the geometry of surveyed faces.

\section{3D Models and Virtual Restoration}

The 'block-by-block' model of the north-eastern corner of the building aids the creation of a database of the blocks and the restoration project [2], thus allowing the simulation of the displacement and also the virtual repositioning of the blocks into their supposed original position.

\footnotetext{
${ }^{2}$ The segmented point cloud was exported into PTS file format and loaded in Rhinoceros 5.0; the vertexes of the box were roughly adapted to the point cloud using the 'gumball' tool; the polygonal model was finally remeshed and fitted onto the point cloud with Rapidform XOS $2^{\circledR}$.
} 
In the first step the upper horizontal plane of the tier was detected; the southern end of the building was used as a reference, since it seems not affected by movements in the structural foundations (figure 11).

Ashlars were then repositioned via roto-translation that sets the upper face of the block on each corresponding horizontal plane. The following virtual repositioning process was used (figure 12): first, reference planes interpolating the upper faces of each block are built and then matched to the reference planes of the tiers with automatic alignment tools ${ }^{3}$. The continuity between the blocks on each tier is restored by translations and rotations around vertical axes. Finally, the broken blocks are virtually reassembled (figure 13).

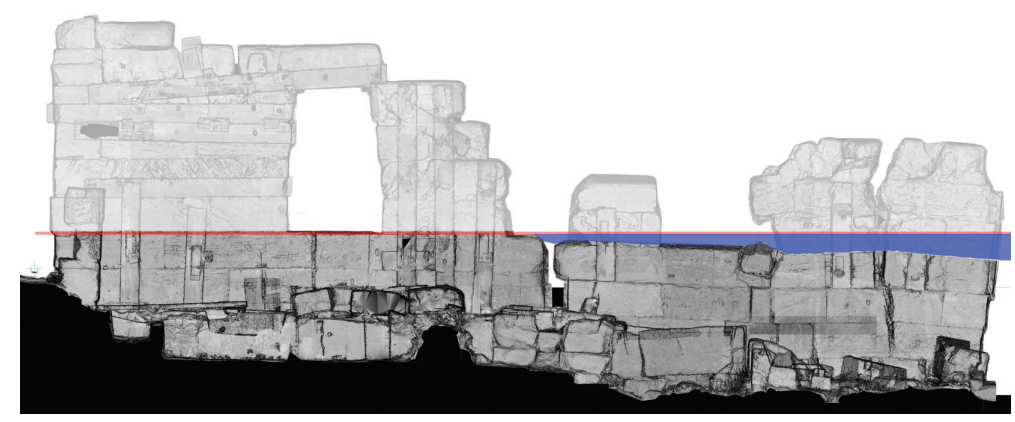

(a)

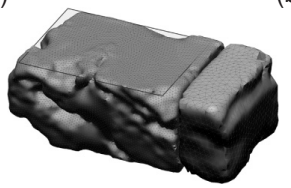

(b)

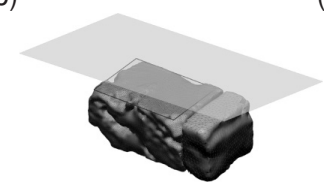

(c)

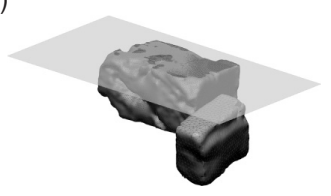

(a)

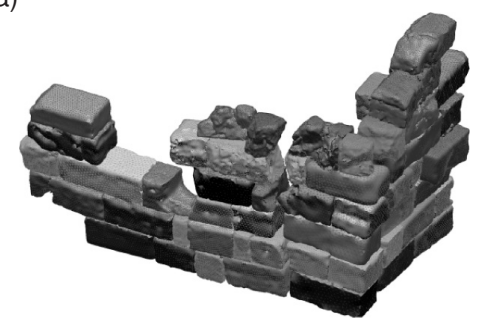

(b)

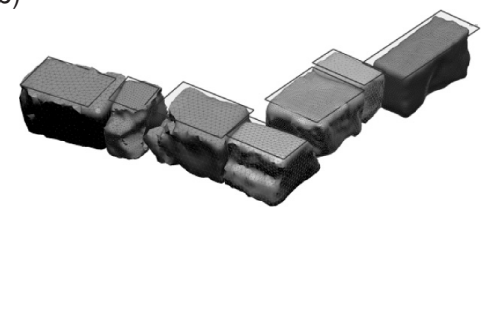

(c)
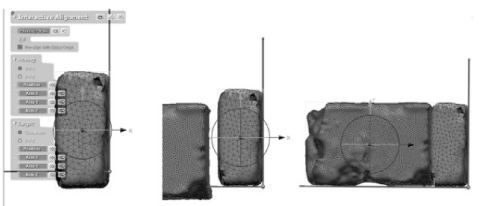

(d)

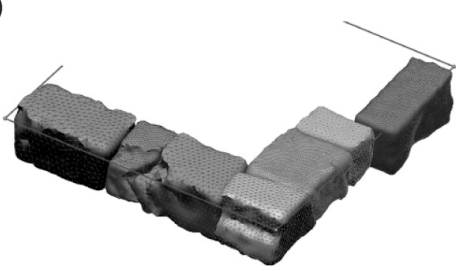

Figure 11. Horizontal plane at the upper face of the ' $G$ ' tier; deviations at the northern end are highlighted in blue.

Figure 12. Orientation of a block: (a) Top plane extraction by interpolation; (b) Reference horizontal plane; (c) Transformation.

Figure 13. The 'block-by-block' model: (a) Model of the northeastern corner of the building; (b) Model of the ' $G$ ' tier in its present state; (c) Blocks' alignment; (d) 'G' tier restored.

\footnotetext{
${ }^{3}$ Automatic alignment has been performed with Rapidform XOS2".
} 


\section{CONCLUSIONS}

Virtual anastylosis of archaeological heritage is a commonplace in the digital era. Temples and ancient monuments are usually rebuilt after studying historic documents or graphic representations in order to show clearly their supposed original state. Such reconstructions are usually for the benefit of tourists or used in the making of movies. This study tested the integration of 3D surveying techniques and digital representation for the purposes of restoration. 3D surveying provided an effective and precise documentation of the constructive elements, thus allowing us to see the distinction between the original features of the building and those due to structural decay. Digital orthophotos effectively illustrate the state of conservation of the surfaces, help to detect the constructive techniques and allow us to identify the elements that were inaccurately placed during previous restorations. Finally, an optimized 3D model of the most decayed area was used to show the set-up of the building after restoration (figure 14, 15).

In the database, still in progress, each block will be indexed by an alphanumeric code that informs us about the tier and the

Figure 14. The north-east corner restored.

Figure 15. Northern end of the East front: (a) Orthophoto; (b) Front view of the $3 \mathrm{D}$ restoration model.

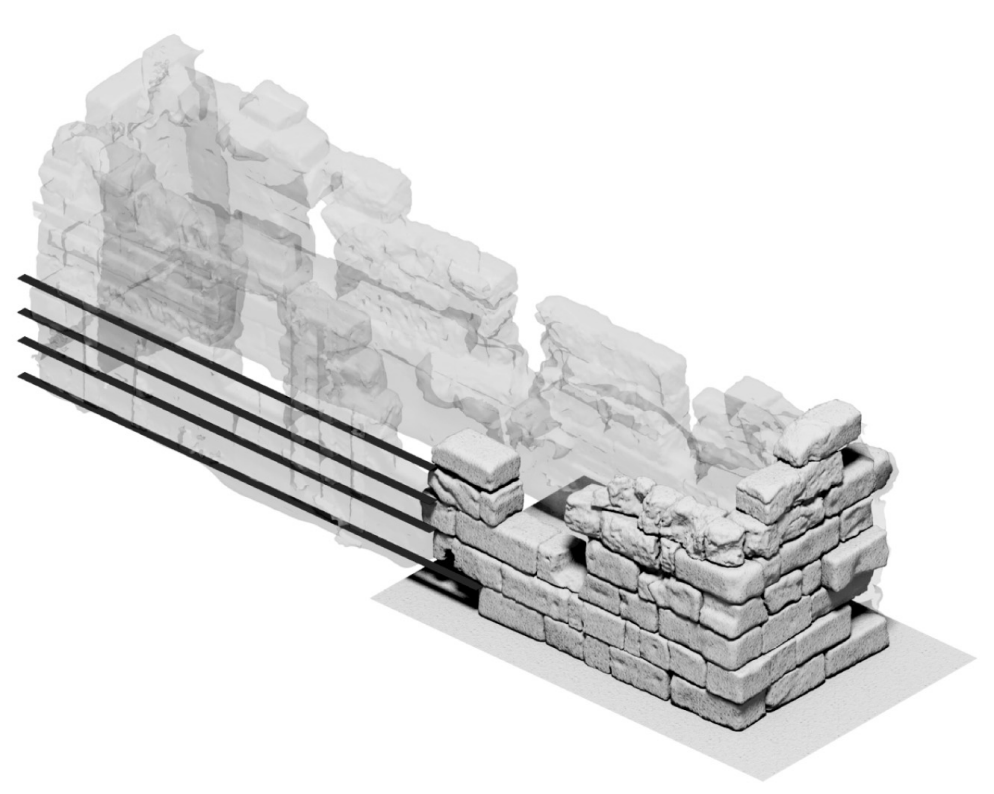

(a)

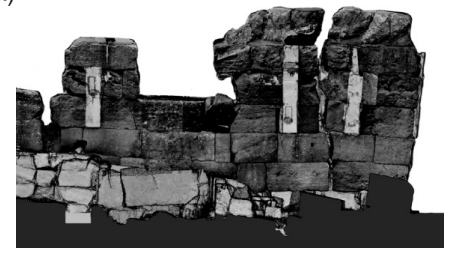

(b)

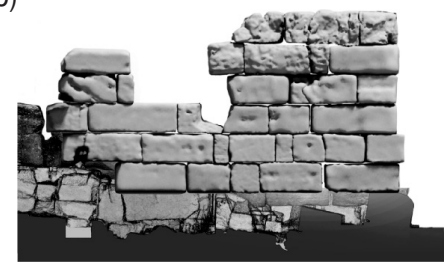


position of the block within it (figure 16). The database will as well document the orientation of the blocks via the identification of its external and upper faces. The code of broken blocks will require an extra number identifying the separate parts. Each block will be linked to a chart (figure 17) where the textual description, the
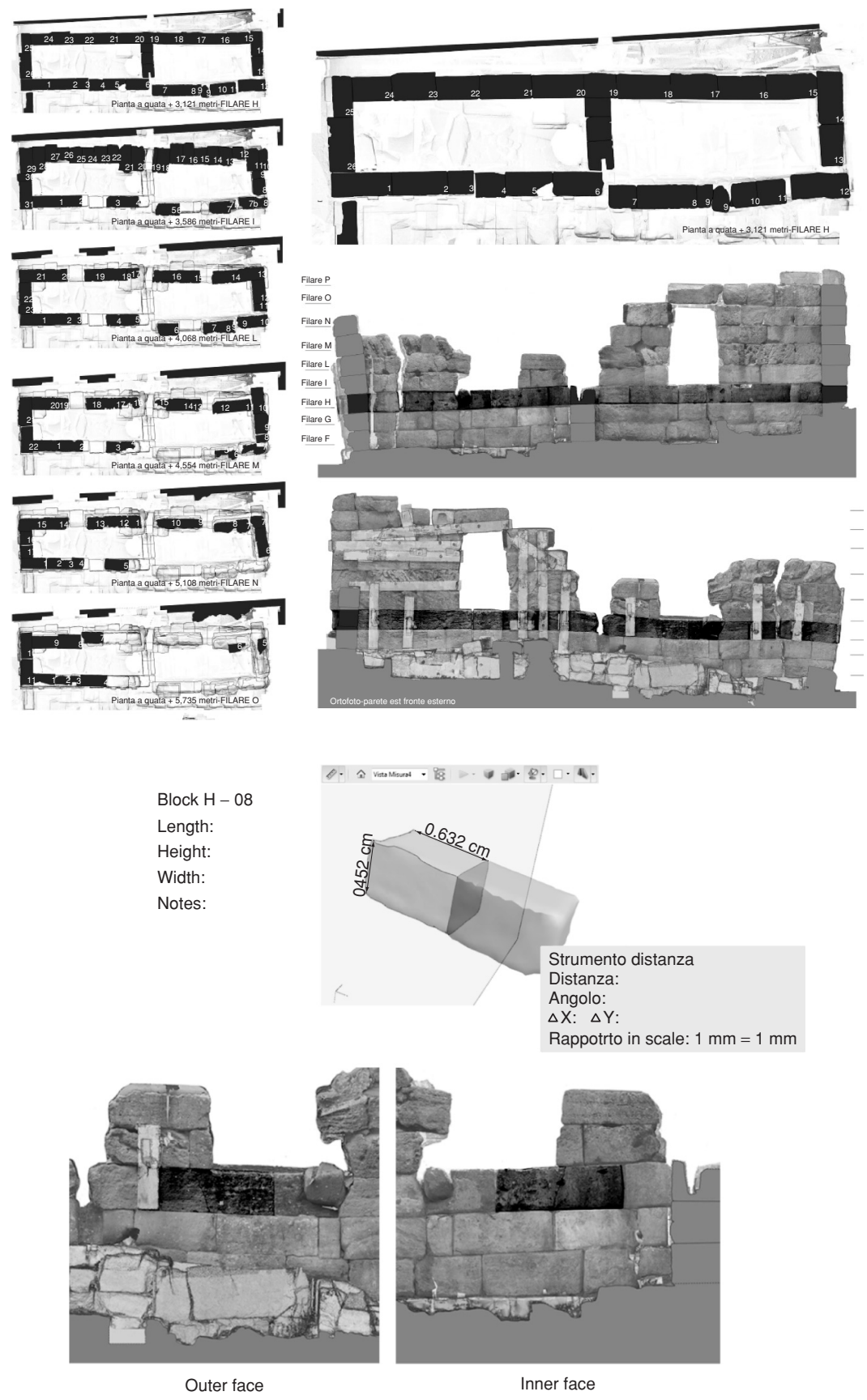

Figure 16. (Left) Plans of the tiers; (Right): Plan and orthophotos of tier ' $G$ '.

Figure 17. Chart of a single block. Upper right corner: 3D model of the block in PDF file format. 
photographic documentation and the 3D model of the block are recorded. All pages and charts in the database are in PDF file format; the visualization of the 3D models and the extraction of information (measures and sections) are performed with Acrobat Reader.

\section{ACKNOWLEDGEMENTS}

The authors wish to thank the "Parco Archeologico" of Agrigento, its Director Arch. Giuseppe Parrello and Arch. Carmelo Bennardo for having supported this study. Arkeorestauri srl, Officina per le Arti Opera srl, Archh. Maria Badalamenti, Fabrizio Verderosa and Tommaso Abbate for having supported surveying.

\section{REFERENCES}

[1] M. Attene, M. Falcidieno, ReMESH: An Interactive Environment to Edit and Repair Triangle Meshes, Proceedings of the IEEE International Conference on Shape Modeling and Applications, 2006, 80, 271-276.

[2] B. Benedetti, M. Gaiani, F. Remondino (editors), Modelli digitali 3D in archeologia: il caso di Pompei, Pisa 2010.

[3] G. Cultrera, Il santuario rupestre presso S. Biagio in Agrigento, Atti della Reale Accademia di Scienze Lettere e Arti di Palermo, 1942-43, voll. II/III, fasc. IV, 609-627.

[4] E. De Miro, Civiltà rupestre dell'Agrigentino: esempi dalla Preistoria al Medioevo. La Sicilia Rupestre nel contesto delle civiltà mediterranee, in C.D. Fonseca (ed.), Atti del VI Convegno Internazionale di Studi sulla civiltà rupestre medievale nel Mezzogiorno italiano, 1986, 235-244.

[5] J.A.K. De Waele, Das Felsheiligtum unter S. Biagio in Agrigento, Bulletin Antieke Beschaving, 1980, 55, 191-202.

[6] S.F. El-Hakim, J.A. Beraldin, Detailed 3d Reconstruction of Monuments Using Multiple Techniques, Proceedings of the International Workshop on Scanning for Cultural Heritage Recording-Complementing or Replacing Photogrammetry, Corfù 2002, 58-64.

[7] P.S. Heckbert, M. Garland, Survey of Polygonal Simplification Algorithms. In "Multiresolution Surface Modeling Course", SIGGRAPH 1997, Course Notes, No. 25.

[8] P. Marconi, Studi agrigentini. Il santuario arcaico delle divinità ctonie, RIASA 1, 1929, 29-68.

[9] A. Siracusano, II santuario rupestre di Agrigento in località S. Biagio, 1983.

[10] C. Zoppi, Gli edifici arcaici del santuario delle divinità ctonie di Agrigento: problemi di cronologia e di architettura, 2001.

[11] C. Zoppi, Le fasi costruttive del cosiddetto santuario rupestre di San Biagio ad Agrigento: alcune osservazioni, Sicilia Antiqva-An International Journal of Archaeology, 2004, 1, 41-79.

[12] F.A. De Fuentes, J.M. Valle Melon, A. Rodriguez Miranda, Model of sources: a proposal for the hierarchy, merging strategy and representation of the information sources in virtual models of historical buildings. CAA conference Proceedings, "Computer Applications and Quantitative Methods in Archaeology", Granada 2010. 
[13] J.M. Valle Melon, A. Lopetegi Galarraga, A. Rodriguez Miranda, Problems when generating virtual models representing real objects: Hondarribia walls. Proceedings of Virtual Retrospect 2005, Bordeaux 2006.

[14] G. Kontogianni, A. Georgopoulos, N. Saraga, E. Alexandraki, K. Tsogka, 3D virtual reconstruction of the Middle Stoa in the Athens Ancient Agora,

Proceedings 3DArch, Trento 2013. 